\title{
Systemic sclerosis-associated pulmonary hypertension: why disease-specific composite endpoints are needed
}

\author{
Christopher P Denton*1, Jerome Avouac'ㄹ, Frank Behrens ${ }^{3}$, Daniel E Furst', Ivan Foeldvari ${ }^{5}$, Marc Humbert ${ }^{6}$, \\ Doerte Huscher? , Otylia Kowal-Bielecka ${ }^{8}$, Marco Matucci-Cerinic ${ }^{9}$, Peter Nash ${ }^{10}$, Christian F Opitz ${ }^{11}$, David Pittrow ${ }^{12}$, \\ Lewis J Rubin ${ }^{13}$, James R Seibold ${ }^{14}$ and Oliver Distler ${ }^{15}$
}

\begin{abstract}
Pulmonary arterial hypertension (PAH) is a serious complication of systemic sclerosis (SSC). In clinical trials $\mathrm{PAH}-\mathrm{SSC}$ has been grouped with other forms, including idiopathic PAH. The primary endpoint for most pivotal studies was improvement in exercise capacity. However, composite clinical endpoints that better reflect long-term outcome may be more meaningful. We discuss potential endpoints and consider why the same measures may not be appropriate for both idiopathic PAH and PAH-SSc due to inherent differences in clinical outcome and management strategies of these two forms of PAH. Failure to take this into account may compromise progress in managing $\mathrm{PAH}$ in SSC.
\end{abstract}

Pulmonary arterial hypertension (PAH) remains an important cause of mortality and morbidity in systemic sclerosis (SSc). Classification of PAH as Group 1 within the Pulmonary Hypertension (PH) WHO clinical classification system has permitted inclusion of patients with SSc in numerous interventional trials and has resulted in the licensing of many agents, including endothelin receptor antagonists [1], type V cGMP phosphodiesterase inhibitors and prostacyclins, including parenteral and inhaled delivery systems. While this has been a fortunate circumstance for our patients, numerous critically important questions remain unaddressed. In general, although the recently updated classification of $\mathrm{PH}$ retains SSc cases within Group 1 [2], evidence suggests that

\footnotetext{
*Correspondence: c.denton@medsch.ucl.ac.uk

'Centre for Rheumatology, Royal Free Campus, University College Medical School, London, NW3 2PF, UK

Full list of author information is available at the end of the article
}

patients with PAH related to SSc (PAH-SSc) show blunted responses to therapy when compared with those with idiopathic $\mathrm{PAH}$, including key measures of outcome such as the six-minute walk test, time to clinical worsening and survival [3]. The very presence of SSc provides an enriched population at high risk of PAH and should offer the opportunity for early diagnosis, yet registry and centre-based data reveal no improvement in referral intervals. Part of this may reflect an increased understanding of the lack of sensitivity and specificity of echocardiography, particularly at the lower end of pulmonary pressures but also because of confounding issues posed by concomitant interstitial lung disease. Finally, patients with SSc tend to be under-represented in modern trials, which are typically rather short in duration (12 to 18 weeks), resulting in inadequacy of data to support definitive recommendations [4].

With this background, there has recently been a systematic effort to improve the assessment of PAH occurring in association with SSc. The main drivers for this have included a desire for better validated endpoints that could be used as a core set applied to clinical trials, the wish for a clinically meaningful endpoint that would reflect practice, and the need for less invasive longitudinal assessment tools that might replace right heart catheterisation (RHC) as the perceived gold standard test for PAH. At present, $\mathrm{RHC}$ is essential for diagnosis but there are questions about the feasibility of this as a tool to follow patients clinically over time. There is clear need for a non-invasive endpoint as well as for validation and critical analysis of the effectiveness of screening modalities. There are particular challenges in addressing this for PAH-SSc, a condition that requires multidisciplinary care and that may present and be followed up by a number of different subspecialists. Each will be an expert in their own field and be familiar with managing and interpreting certain investigations but there will be differences of opinion between the different experts as to what the best tests are and how they should be interpreted and used in 
practice. In addition, the tools that may be validated in other forms of PAH are unlikely to have been formally assessed in PAH-SSc, which has its own unique characteristics that may affect standard PAH outcome measures; an example would include the associated musculoskeletal manifestations. Moreover, there may be differences for other forms of connective tissue diseaseassociated PAH. There are biases introduced based upon different clinical experiences and also related to the familiarity with clinical trials.

An approach that has been used successfully in rheumatology and has a clearly defined framework is covered by the Outcome Measures in Rheumatology (OMERACT) methodology. This uses a standardised framework to assess potential disease measures for clinical trials to consider utility under the subcategories of the OMERACT filter [5]. The Expert Panel on Outcomes measures in PAH related to Systemic Sclerosis (EPOSS)OMERACT group was established to begin to apply this approach to evaluating PAH-SSc. This group has integrated expertise in cardiology, pulmonary medicine, rheumatology and biostatistics as well as clinical trial design and outcome development and validation. It has applied the OMERACT filter to individual tools that could represent endpoints in trials and has critically reviewed the published literature to explore the extent to which outcomes have been validated. In addition, it has sought to develop consensus about individual outcomes. In particular, the EPOSS group has identified through a Delphi process a series of recommended domains and their assessment tools [6]. The data that could validate these tools have been considered systematically and this has led to a series of important observations. One of the goals was to identify a measure or series of measures that could replace RHC as the gold standard of assessment. These are significant achievements and have resulted in a series of relevant publications. So far, six substantive papers [6-11] have been published as a direct result of the EPOSS initiative, and more are expected.

Work is now underway and there will be attempts to validate the individual components and to review the available data that provide some validation. This is a daunting task as for many tools there are not sufficient results from research studies to undertake this. First attempts to evaluate the routine clinical tool of Dopplerechocardiography are testament to the challenge that lies ahead [7]. An important output of this exercise has been the definition of research agenda to prioritise effort in addressing the data that are available and determine the extent to which the available information from national (such as the French Intinair project [12], UK single centre registries and compERA-XL [13]) or from clinical trial datasets might be interrogated. One limitation of most clinical trials is that they usually include a minority, typically around $20 \%$, of cases with connective tissue disease-associated PAH, and fewer with PAH-SSc. The EPOSS group provides a template for the type of international multidisciplinary approach that could tackle these important challenges.

In the meantime the clinical arena has moved on and a large number of major clinical trials in PAH include cases of PAH-SSc. There has been the strong suggestion that a composite endpoint that reflects clinical practice be used. This has become defined as the time to clinical worsening (TTCW). A formal measure of TTCW has emerged as an attractive composite endpoint that measures progression in PAH. It was originally included as a secondary endpoint in several major clinical trials that led to licensing of PAH therapies based upon a primary endpoint of change in exercise capacity (the six-minute walk test). At face value it makes obvious sense, especially as a clinically meaningful endpoint that may be used in licensing and in post-licensing evaluation of therapies. However, the devil is in the detail. Different studies have used different components in the TTCW definition and there are major potential local differences in practice that may make a measure unworkable or unreliable in different centres. Thus, some centres have an outpatient ambulatory emphasis whereas others may often hospitalise cases of $\mathrm{PAH}$. In addition, availability of therapies and expertise in procedures such as surgical intervention or transplantation may be relevant. Moreover, as discussed above, it is likely that different standards may be applicable for PAH-SSc versus idiopathic PAH due to comorbidity and potential differences between outcome and progression of PAH and suitability for treatments. In the short term, TTCW is very likely to be adopted as a useful measure and one that is especially relevant in early stage disease where stabilisation can be a very appropriate management goal. However, this should serve as an impetus to further research to validate and understand individual components of TTCW and develop new and potentially better composite tools. In particular, there are self-evident reasons why some of the components of TTCW are likely to be unreliable or incomparable in PAH-SSc. Musculoskeletal involvement and comorbidity, such as lung fibrosis or cardiac complications, are clearly likely to affect exercise capacity. One study suggests that musculoskeletal deconditioning is the major determinant of six-minute walk test distance [14], and no relationship with parameters of lung function has been shown [15]. There are multiple causes of diseaserelated mortality in SSc - for example, renal crisis, lung fibrosis and gut disease - and so mortality cannot be taken as a surrogate for PAH outcome. Finally, comorbidity and age make PAH-SSc cases much less likely than idiopathic PAH to be referred for transplantation and even less likely to be transplanted. The impact of 
Table 1. Domains and measurement tools for the assessment of pulmonary arterial hypertension in systemic sclerosis

\begin{tabular}{|c|c|c|}
\hline Domain & Measurement tools & Specific points to consider in application to $\mathrm{PAH}-\mathrm{SSC}^{\mathrm{a}}$ \\
\hline Lung vascular & $\begin{array}{l}\text { Right heart catheter, } \\
\text { echocardiography }\end{array}$ & $\begin{array}{l}\text { Other forms of PAH are prevalent in SSc, including type II (cardiac disease) and type III (lung fibrosis) } \\
\text { and confound assessment, especially by echocardiography }\end{array}$ \\
\hline Exercise testing & $\begin{array}{l}6 \mathrm{MWD} \text {, oxygen saturation } \\
\text { at exercise }\end{array}$ & $\begin{array}{l}\text { Musculoskeletal involvement and deconditioning have a major impact on exercise capacity in SSc in } \\
\text { addition to PAH }\end{array}$ \\
\hline Cardiac function & $\begin{array}{l}\text { Right heart catheter, } \\
\text { echocardiography }\end{array}$ & $\begin{array}{l}\text { Cardiac abnormalities (diagnosed and undiagnosed) are prevalent in SSc, including high frequency of } \\
\text { diastolic dysfunction }\end{array}$ \\
\hline Dyspnea & Dyspnea VAS & $\begin{array}{l}\text { There are multiple non-PAH causes for dyspnoea in SSc (lung fibrosis, deconditioning, anaemia, } \\
\text { cardiac disease) }\end{array}$ \\
\hline $\begin{array}{l}\text { Discontinuation } \\
\text { of treatment }\end{array}$ & $\begin{array}{l}\text { Adverse events, serious } \\
\text { adverse events }\end{array}$ & Concomitant medication for SSc or co-morbidity may impact on adverse events \\
\hline Quality of life & SF-36, HAQ DI & Extra-pulmonary involvement has a major impact on health status and function in SSC \\
\hline $\begin{array}{l}\text { Global state by } \\
\text { physician }\end{array}$ & Survival & SSc-PAH currently has a substantially worse mortality than iPAH \\
\hline
\end{tabular}

${ }^{a}$ Domains identified through the EPOSS initiative may be integrated into the TTCW composite end-point and whether these may be different for idiopathic pulmonary arterial hypertension and pulmonary arterial hypertension associated with systemic sclerosis (PAH-SSc). 6MWD, 6-minute walking distance; HAQ DI = Health Assessment Questionnaire Disability Index; iPAH, idiopathic pulmonary arterial hypertension; PAH, pulmonary arterial hypertension; SF-36, Short Form 36 score; SSc, systemic sclerosis; VAS, visual analog scale.

these individual component differences may be cancelled out in a composite score but this cannot be assumed. This should be considered especially in subtypes of PAH and so the research work now emerging from the EPOSS initiative is likely to be very relevant. In the meantime, the recent report from the Fourth World Congress in $\mathrm{PH}$ in Dana Point, USA, represents current best expert consensus on how to standardise and use TTCW as an outcome measure in PAH clinical trials [16]. It seems likely that TTCW will be a benchmark in future studies. It has already replaced exercise capacity assessed by the six-minute walk test distance, generally now there is a move towards a robust hemodynamic endpoint or the composite clinical measure.

So where does that leave the EPOSS initiative? The work could be regarded as done and the TTCW be adopted as a gold standard. RHC would remain for diagnosis but would only be performed later as directed clinically. But this would not be a correct approach for PAH-SSc. Table 1 highlights some specific aspects that would be relevant to the domains and measures that have been identified through the EPOSS initiative and that may be incorporated into composite endpoints, including TTCW. There is a strong need for systematic validation and much to be learnt from the defined research agendas along the way. The two concepts must co-exist but cannot do so without interplay so that both may inform the other. It can be argued that rigorous concerns about validity of endpoints could have severely impeded progress and treatment opportunities but the challenge must now be faced so that there is a real consensus that can be applied and eventuality the clinical needs of patients and the methodological needs of trialists and the exacting standards of the regulatory authorities that license new agents can all be met. For the time being TTCW is probably the most usable endpoint for clinical studies but the component terms need better standardisation and must be clearly defined. In the future, through initiatives such as EPOSS, these components can be validated in PAH-SSc and it is imperative that the challenge of this task is not used as justification for not addressing these important questions.

\begin{abstract}
Abbreviations
OMERACT, Outcome Measures in Rheumatology; PAH, pulmonary arterial hypertension; $\mathrm{PH}$, pulmonary hypertension; $\mathrm{RHC}$, right heart catheterisation; SSc, systemic sclerosis.
\end{abstract}

\section{Competing interests}

The authors declare that they have no competing interests.

\section{Author details}

${ }^{1}$ Centre for Rheumatology, Royal Free Campus, University College Medical School, London, NW3 2PF, UK. ${ }^{2}$ Rheumatology A Department, RDU, Paris, 75006, France. ${ }^{3}$ German Rheumatism Research Centre, 10117 Berlin, Germany. ${ }^{4}$ Division of Rheumatology, Department of Medicine, David Geffen

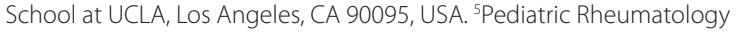
Clinic, General Hospital Eilbek, 22081 Germany. ${ }^{6 S}$ Service de Pneumologie et Reanimation Respiratoire, Centre des Maladies Vasculaires Pulmonaires, Hopital Antoine-Beclere, Université Paris-Sud, Clamart, 92140, France. ${ }^{7}$ Division of Rheumatology/ZAFES, JW Goethe University, 60325 Frankfurt, Germany. ${ }^{8}$ Department of Rheumatology and Internal Medicine, Medical University of Bialystok, 15-089, Poland. ${ }^{9}$ Department of Medicine, Division of Rheumatology, Denothe Center, University of Florence, 50134, Italy. ${ }^{10}$ Rheumatology Research Unit, Cotton Tree, Sunshine Coast, Queensland, 4558, Australia. ${ }^{11}$ Klinik für Innere Medizin, DRK-Kliniken Berlin Köpenick, 12559 Berlin, Germany. ${ }^{12}$ Institute for Clinical Pharmacology, Medical Faculty, Technical University, 01187 Dresden, Germany. ${ }^{13}$ Division of Pulmonary and Critical Care Medicine, University of California, San Diego School of Medicine, La Jolla, CA 92093-0348 USA. ${ }^{14}$ Scleroderma Research Consultants, CT 06001, USA. ${ }^{15}$ Department of Rheumatology, University Hospital Zurich, CH-8091, Switzerland.

Published: 20 June 2011

\section{References}

1. Simonneau G, Galiè N, Rubin LJ, Langleben D, Seeger W, Domenighetti G, Gibbs S, Lebrec D, Speich R, Beghetti M, Rich S, Fishman A: Clinical classification of pulmonary hypertension. J Am Coll Cardiol 2004, 43(12 Suppl S):5S-12S. 
2. Simonneau G, Robbins IM, Beghetti M, Channick RN, Delcroix M, Denton CP, Elliott CG, Gaine SP, Gladwin MT, Jing ZC, Krowka MJ, Langleben D, Nakanishi N, Souza R: Updated clinical classification of pulmonary hypertension. J Am Coll Cardiol 2009, 54(1 Suppl):S43-54.

3. Kabunga P, Coghlan G: Endothelin receptor antagonism: role in the treatment of pulmonary arterial hypertension related to scleroderma. Drugs 2008, 68:1635-1645

4. Macchia A, Marchioli R, Marfisi R, Scarano M, Levantesi G, Tavazzi L, Tognoni G: A meta-analysis of trials of pulmonary hypertension: a clinical condition looking for drugs and research methodology. Am Heart J 2007, 153:1037-1047.

5. Furst D, Khanna D, Matucci-Cerinic M, Clements P, Steen V, Pope J, Merkel P, Foeldvari I, Seibold J, Pittrow D, Polisson R, Strand V: Systemic sclerosis continuing progress in developing clinical measures of response. J Rheumatol 2007, 34:1194-1200.

6. Distler O, Behrens F, Pittrow D, Huscher D, Denton CP, Foeldvari I, Humbert M, Matucci-Cerinic M, Nash P, Opitz CF, Rubin LJ, Seibold JR, Furst DE; EPOSS-Omeract Group: Defining appropriate outcome measures in pulmonary arterial hypertension related to systemic sclerosis: a Delphi consensus study with cluster analysis. Arthritis Rheum 2008, 59:867-875.

7. Sánchez-Román J, Opitz CF, Kowal-Bielecka O, García-Hernández FJ, Castillo-Palma MJ, Pittrow D; EPOSS-OMERACT Group: Screening for PAH in patients with systemic sclerosis: focus on Doppler echocardiography. Rheumatology (Oxford) 2008, 47 Suppl 5:v33-35.

8. Huscher D, Pittrow D, Distler O, Denton CP, Foeldvari I, Humbert M, Matucci-Cerinic M, Kowal-Bielecka O, Avouac J, Behrens F, Nash P, Opitz CF, Rubin LJ, Seibold JR, Strand V, Furst DE; EPOSS-OMERACT Group: Interactions between rheumatologists and cardio-/pulmonologists in the assessment and use of outcome measures in pulmonary arterial hypertension related to systemic sclerosis. Clin Exp Rheumatol 2010, 28(2 Suppl 58):S47-52.

9. Avouac J, Kowal-Bielecka O, Pittrow D, Huscher D, Behrens F, Denton CP,Foeldvari I, Humbert M, Matucci-Cerinic M, Nash P, Opitz CF, Rubin L, Seibold JR, Distler O, Furst DE; EPOSS Group: Validation of the 6 min walk test according to the OMERACT filter: a systematic literature review by the EPOSS-OMERACT group. Ann Rheum Dis 2010, 69:1360-1363.

10. Kowal-Bielecka O, Avouac J, Pittrow D, Huscher D, Behrens F, Denton CP,Foeldvari I, Humbert M, Matucci-Cerinic M, Nash P, Opitz CF, Rubin L, Seibold JR, Strand V, Furst DE, Distler O; EPOSS Group: Echocardiography as an outcome measure in scleroderma-related pulmonary arterial hypertension: a systematic literature analysis by the EPOSS group. J Rheumatol 2010, 37:105-115.
11. Khanna D, Distler O, Avouac J, Behrens F, Clements PJ, Denton C, Foeldvari I, Giannini E, Huscher D, Kowal-Bielecka O, Lovell D, Matucci-Cerinic M, Mayes M,Merkel PA, Nash P, Opitz CF, Pittrow D, Rubin L, Seibold JR, Steen V, Strand CV, Tugwell PS, Varga J, Zink A, Furst DE; CRISS; EPOSS: Measures of response in clinical trials of systemic sclerosis: the Combined Response Index for Systemic Sclerosis (CRISS) and Outcome Measures in Pulmonary Arterial Hypertension related to Systemic Sclerosis (EPOSS). J Rheumatol 2009, 36:2356-2361

12. Pittrow D, Ghofrani HA, Opitz CF, Huscher D, Hoeper MM: International, prospective register for the documentation of first-line and maintenance therapy in patients with pulmonary hypertension (CompERA-XL)]. Dtsch Med Wochenschr 2009, 134 Suppl 5:S173-175.

13. Hachulla E, de Groote P, Gressin V, Sibilia J, Diot E, Carpentier P, Mouthon L, Hatron PY, Jego P, Allanore Y, Tiev KP, Agard C, Cosnes A, Cirstea D, Constans J, Farge D, Viallard JF, Harle JR, Patat F, Imbert B, Kahan A, Cabane J, Clerson P, Guillevin L, Humbert M: The three-year incidence of pulmonary arterial hypertension associated with systemic sclerosis in a multicenter nationwide longitudinal study in France. Arthritis Rheum 2009, 60:1831-1839.

14. de Oliveira NC, dos Santos Sabbag LM, Ueno LM, de Souza RB, Borges CL, de Sá Pinto AL, Lima FR: Reduced exercise capacity in systemic sclerosis patients without pulmonary involvement. Scand J Rheumatol 2007, 36:458-4561

15. Buch MH, Denton CP, Furst DE, Guillevin L, Rubin LJ, Wells AU, Matucci-Cerinic M, Riemekasten G, Emery P, Chadha-Boreham H, Charef P, Roux S, Black CM, Seibold JR: Submaximal exercise testing in the assessment of interstitial lung disease secondary to systemic sclerosis: reproducibility and correlations of the 6-min walk test. Ann Rheum Dis 2007, 66:169-173.

16. McLaughlin W, Badesch DB, Delcroix M, Fleming TR, Gaine SP, Galiè N, Gibbs JS, Kim NH, Oudiz RJ, Peacock A, Provencher S, Sitbon O, Tapson VF, Seeger W End points and clinical trial design in pulmonary arterial hypertension. J Am Coll Cardiol 2009, 54(1 Suppl):S97-107.

doi:10.1186/ar3346

Cite this article as: Denton CP, et al: Systemic sclerosis-associated pulmonary hypertension: why disease-specific composite endpoints are needed. Arthritis Research \& Therapy 2011, 13:114 